\title{
Intergenerational relationships: do older adults experience ambivalence with their adult children?
}

\author{
Sofia von Humboldt (iD) ${ }^{a}$, Andrea Costa ${ }^{a}$, Mariline Fernandes ${ }^{b}$, Sara Silva ${ }^{a}$, and Isabel Leal (D) \\ aWilliam James Center for Research, ISPA - Instituto Universitário, Lisbon, Portugal; 'bFaculdade de Psicologia, \\ Universidade Lusíada, Lisbon, Portugal
}

\begin{abstract}
This study aims to analyze the perspectives of intergenerational relationships between older adults and adult children. For this purpose, a qualitative research was carried out, which analyzes these relations at a cross-national level. Four hundred and twenty four older participants aged 65-97 years, were interviewed. Participants were of three different nationalities and lived in the community. All the interviews went through the process of verbatim transcription and subsequent content analysis. Two dimensions of generational ambivalence were revealed from the study; support and the conflict dimensions. Findings of content analysis produced six themes, which represent intergenerational relations between older adults and adult children: older adults-adult children interaction quality; family integration; care and support; definition of limits; distance and alienation; and communication difficulties. This study highlighted the diversity of experiences in old age, in relation to intergenerational relationships and underlined the conflicting expectations from older adults in relation to their adult children.
\end{abstract}

\section{Introduction}

Old people are living longer and with better quality of life (World Health Organization, 2018; von Humboldt \& Leal, 2014). Intergenerational relationships have an impact in well-being and provide a self-perceived value, which is associated to aging well (Lowenstein et al., 2011). Families are relevant for older adults' well-being. The relationship between older adult parents and their adult children frequently involves contact and exchange of support, possible closeness, and both positive and negative emotions (Government Office for Science, 2015; Lowenstein et al., 2011; Rabelo \& Neri, 2014).

Family may be a facilitator of the emotional balance of older adults, however conflict and ambivalence may also occur. Although most older adults are in good health, illness and dependence are constructs that can affect the balance of family structure and care capacity (Rabelo \& Neri, 2014). When care is needed and lack of autonomy becomes a daily challenge, emotional stress, ambivalence and conflict may be present in old parents-adult children relationships (Rabelo \& Neri, 2014; Sechrist et al., 2012). Family relationships may also comprise abuse of power (e.g., physical or psychological), harm and threats (Brito \& Faleiros, 2009), injuries, illness, loss of productivity, isolation, depression and despair (Rabelo \& Neri, 2014; von Humboldt et al., 2015). In this context, there are three prominent theoretical perspectives in the literature on the emotional quality of the parent-child relationship: the theory of solidarity (Bengtson \& Roberts, 1991), the conflict model (Clarke et al., 1999) and ambivalence theory (Luscher \& Pillemer, 1998). 
The intergenerational ambivalence construct has gained increasing relevance for understanding the intricacy of aging families (Lendon, 2017). Luscher and Pillemer (1998) firstly proposed a theoretical concept concerning intergenerational ambivalence, arguing that ambivalence should not be equated with conflict. Moreover, Ka-Wing (2017) proposed the concept of ambivalence. His construct indicates the existence of simultaneously contradictory feelings and emotions. The theory of intergenerational ambivalence attempts to overcome the dichotomous congruence implicit in the theories of intergenerational solidarity and conflict, but is not entirely successful (Luscher, 2004, 2005), considering that, researchers have focused on intergenerational norms or relations, neglecting ambivalence ((Luscher, 2000; Luscher \& Lettke, 2004; Park, 2014; Prinzen, 2014).

Intergenerational exchanges depend on the intensity and nature of the bonds built and experienced in and throughout the family dynamics (Park, 2014; Pimentel, 2005). Relationships between older adults and their adult children may involve great emotional complexity and the quality of these relationships is frequently associated with their physical and mental health, with implications in the perception of family functioning and structure (Park, 2014; Silverstein, 2006; Torres \& Cao, 2019; von Humboldt et al., 2018).

Older adults may assume the role of linking generations, transmitting values and traditions, and as role models for their adult children (who may be parents as well) on educating their children, taking care temporarily, being mentors, or providing support in moments of crisis (Dias, 2008; Kaufman \& Elder, 2003). Previous studies indicate that the intergenerational resources transferred between older parents and adult children may be based on altruism and reciprocity. An altruistic perspective posits that each generation provides for another generation based on need, e.g., if older parents provide money to adult children with poor economic resources, parents may expected that adult children may provide social support and care to older parents with poor health (Kunemund et al., 2005). According to Silverstein et al. (2002), adult children who received emotional and financial support from their parents provide social support to their parents, which suggest that reciprocal exchanges (e.g., health and financial resources) between generations stretch over a large part of the family life cycle (Suitor et al., 2007).

The literature indicates that gender differences may also affect the relationship between older adults and their adult children. In particular, daughters are more emotionally involved with their parents. Hence, women are more likely to report conflict, stress and ambivalence (Lowenstein, 2007; Rabelo \& Neri, 2014).

Moreover, studies indicate that relationships between older parents and adult children may be affected by grandparent-grandchildren relationships. In fact, close interactions due to obligation or need (e.g., care-taking of grandchildren, taking them to school, being educators, mentors and confidants) may be linked to unsatisfactory, ambivalent and conflictive relationships between older parents and adult children (Cardoso, 2011; Cerveny et al., 2012; Dias, 2008, 2008; Drew \& Silverstein, 2007; Kunemund et al., 2005: Mendoza-Ruvalcaba et al., 2017; Smith \& Drew, 2004).

Studies on intergenerational relations from the different points of view of the generations involved are gradually emerging in the literature (von Humboldt et al. 2014; Lendon et al., 2014: Steinbach, 2012; Torres \& Cao, 2019; von Humboldt, Low et al., 2020; von Humboldt et al., 2018). In particular, studies that involve older adult perceptions are still scarce. Additionally, further cross-cultural studies are necessary on how older adults experience the dynamics as ambivalent. Thus, the objective of this qualitative study is to analyze how older adults experience intergenerational relationships with adult children.

\section{Methods}

\section{Recruitment and sampling}

The present study aims to assess the older adult perspectives on intergenerational relationships with their adult children. Qualitative data were collected through interviews with older adults of different 
nationalities, namely English, German and Portuguese. Participants lived in the community, in their own homes. This study encompassed comparable data from the three different nationalities. Four hundred and seventy older adults were contacted through local community center databases to participate in the study through in-person interviews. The contact database was for the metropolitan area of Lisbon and the Algarve, in Portugal.

Participants were nationally diverse (English, German and Portuguese) and resided in Portugal for more than 10 years. The participant's nationality was assessed based on their place of birth. Because Lisbon and the Algarve are the two most important regions of residence of the foreign community, the ex-patriate participants were recruited in the cited locations. The participation of older adults in the interviews was voluntary, and $90 \%$ of the all participants gave permission for participating in the study. All interviews were conducted and recorded in participants' homes, in Portuguese and English, and transcribed verbatim. These were subsequently translated to English language by bilingual researchers for content analysis.

The interviewers explained the purpose as well as the content of the interviews to the participants. Altogether, 424 older adults participated, aged 65 years and older (range 65-97 years) (see Table 1). From the total sample, $62.5 \%$ were women, the majority $(61.8 \%)$ had a partner and $87.5 \%$ were employed before retirement. The remaining participants were not available or able to participate in the study.

Prior to the interviews, the 424 participants gave the interviewers their informed consent. Participants were selected for the study, through a clinical interview for cognitive ability, medical and psychiatric disorders, drugs that affect cognition and substance use. The older adults reported having regular contact with their adult children, that is, one contact or more per month. The William James Center for Research, in ISPA - University Institute, approved all the procedures.

The interviews occurred from February to November 2016. Participants were interviewed in person, over 20 to 40 minutes. Participants were invited to participate in the study on a voluntary

Table 1. Sample socio-demographic characteristics.

\begin{tabular}{|c|c|}
\hline Characteristics & $(n=424)$ \\
\hline Age, mean \pm SD & $73.2 \pm 6.1$ \\
\hline \multicolumn{2}{|l|}{ Gender, n (\%) } \\
\hline Women & $265(62.5)$ \\
\hline Man & $159(37.5)$ \\
\hline \multicolumn{2}{|l|}{ Living Status, n (\%) } \\
\hline Alone & $88(20.7)$ \\
\hline With sons & $8(1.8)$ \\
\hline With a partner & $258(60.8)$ \\
\hline Partner and other relatives & $70(16.7)$ \\
\hline \multicolumn{2}{|l|}{ Nationality, n (\%) } \\
\hline English & $142(33.6)$ \\
\hline German & $138(32.5)$ \\
\hline Portuguese & $144(33.9)$ \\
\hline \multicolumn{2}{|l|}{ Education n (\%) } \\
\hline Primary school & $132(31.2)$ \\
\hline Middle school & $180(42.4)$ \\
\hline$\geq$ High school & $112(26.4)$ \\
\hline \multicolumn{2}{|l|}{ Marital Status n (\%) } \\
\hline Married or in a relationship & $262(61.8)$ \\
\hline Not Married or in a relationship & $162(38.2)$ \\
\hline \multicolumn{2}{|l|}{ Professional Status n (\%) } \\
\hline Active & $125(29.5)$ \\
\hline Inactive & $299(70.5)$ \\
\hline \multicolumn{2}{|l|}{ Family Annual Income n (\%) } \\
\hline$\leq 25,000 €$ & $199(46.9)$ \\
\hline$>25,000 €$ & $225(53.1)$ \\
\hline \multicolumn{2}{|l|}{ Perceived Health n (\%) } \\
\hline Good & $251(59.1)$ \\
\hline Poor & $173(40.9)$ \\
\hline
\end{tabular}


basis, and could withdraw at any time. Additionally, participants were given liberty to share life experiences regarding relationships with their adult children. Interviewers paid special attention to how the interviews were conducted, leaving participants at ease to share their perspectives on intergenerational relationships with adult children in different cultures.

Semi-structured interviews began with a common question on personal meaning of intergenerational relationships for older adults. The interviewer addressed the "intergenerational relations" construct without sharing a formal definition, since the purpose of the study was to identify the perspectives of intergenerational relationships between the older adults and their adult children. The interviewer registered the responses of the participants, introducing questions when clarification was needed.

Interviews were accompanied by reminders about the purpose of the study, and participants were reassured that they could finish the interview at any time. If participants lived with their spouses or partners, they were asked to complete interviews alone with the interviewers, which was achieved in all instances.

The themes comprised intergenerational relationships with adult children, situations and variables that influenced the relationships and issues of older adults with intergenerational relationships. The quality of data collection was monitored by the interview team during meetings. The review board of the William James Center for Research, the ISPA - Instituto Universitário, and the Portuguese Foundation for Science and Technology (FCT) approved this study.

\section{Data analysis}

Qualitative interviews had the objective of exploring individual perspectives on the subject of intergenerational relations with adult children, in different cultures. In addition, specific questions about situations and factors in intergenerational relationships were included, as well as concerns of older adults.

After an analysis of the transcripts, the interviewers were faced with distinct references used by the participants to build the construct. To analyze the interviews data, a continuous comparative method was used (von Humboldt, \& Leal, 2015a).

To increase the reliability of the coding procedure, researchers trained in gerontology analyzed the structure during several debriefing sessions between peers (von Humboldt, \& Leal, 2015b) and reviewed them adequately.

Two researchers manually encoded a random sample of $25 \%$ of the transcripts, with the aim of elaborating a more effective interpretation of convergence (von Humboldt et al., 2020). The coded transcripts were evaluated for internal consistency and later the structure was altered, based on the agreement of peers.

In the coding phase, categories were revised until there is no new theme or data, achieving theoretical saturation. After the transcriptions were coded, the data were examined and we verified whether they fell into similar contexts or whether they should be divided into codes, themes and subthemes. Next, final codes were hierarchically organized into codes, subthemes, and themes. Coding reports were reviewed and cross-checked to achieve consistency of interpretation. Whenever different interpretations existed, transcripts were again analyzed and discussed by the researchers, in order to reach a consensus regarding the emerging themes and sub-themes. After the discussion of codes, $7 \%$ were determined not relevant to the research questions, and excluded from the analysis.

To evaluate the consonance among researchers, in the process of coding the transcripts of the participants within the different categories, Cohen kappa scores were calculated. Based on the k-value of the previous investigations, Cohen's kappa scores for reliability among evaluators proved to be almost perfect for the following topics: family integration $(k=.97, p<.01)$, distance and alienation $(k=$ $.88, p<.01)$, older adult - adult child interaction quality $(k=96, p<.01)$, definition of limits $(k=.79$, $p<.01)$, care and support $(k=.83, p<.01)$ and communication difficulties $(k=.94, p<.01)$. 
The extracts of the coded interviews were analyzed for subsequent elaboration of an interpretative framework of results, to analyze the patterns in intergenerational relationships of older adults with adult children (Carneiro et al., 2014).

\section{Results}

Intergenerational relationships comprised two dimensions of ambivalence (supportive and conflictual). We analyzed non-mutually exclusive themes that comprised the variety of participant experiences.

These participants rarely openly used the word "ambivalent", however their narratives about relationships with their adult children were simultaneously supportive (e.g., family integration) and conflictual (e.g., distance and alienation).

\section{Conceptualizing support}

Participants verbalized relationships with at least one of their adult children as supportive. Portuguese respondents showed the highest frequency of supportive relationships (42.1\%), followed by English (30.0\%) and German (27.9\%) older adults. Supportive relationships were reflected in three themes: older adult-adult children interaction quality, family integration, and care and support.

\section{Theme 1: older adult-adult children interaction quality}

Respondents $(n=126)$ indicated quality in their relations with adult children. They also highlighted that quality and interest in the relationships were more relevant that the frequency of visits. All three nationalities verbalized interaction quality as the most frequent theme $\left(n_{\text {Port }}=56 ; n_{\text {Germ }}=42, n_{\text {Eng }}=\right.$ 28). These participants verbalized that support occurred when intergenerational relationships included quality and motivation, that is, relationships were richer in affects for those who felt quality, interest and motivation in relations with their adult children.

Family relations gain importance in old age as they provide the necessary security and support for adjustments required by the new contexts of life. Laura expressed her idea: "I invest in our relationship since it also benefits myself and my children: we have more experience and wisdom to give them and in turn, we get interest and quality."

Having a quality relationship with my children was an important factor, much more than living close by. "We only see each other twice a year but we have long and profound conversations, I love those moments." said Dalila happily.

In addition, divorce may also influence the quality of the relationship between older adults and adult children. Luana explained, "Although we are divorced, we try to have contact with our children the same way. Neither of them likes when I talk about my relationship with my ex-husband, thus I choose topics of conversation that do not include my ex-husband."

\section{Theme 2: family integration}

Participants $(n=112)$ verbalized they felt integrated in family plans and stressed that this integration contributed to their well-being. All three nationalities verbalized family integration as the second most frequent theme $\left(n_{\text {Port }}=45 ; n_{\text {Eng }}=34, n_{\text {Ger }}=33\right)$.

These respondents felt integrated in family activities with their children. Moreover, they expressed that their presence was required and they felt they contributed to family dynamics, for example, in special family events.

Overall, older adults have always been very attached to the family topic. Family gatherings were a positive example for family integration. Joseph reported that "Christmas is always special for me. 
However sometimes I feel sadness because our children are separated and I cannot see them every year."

In a different perspective, Maria indicated: "I remember in the old days that I did not have much contact with my children. Unlike now, I help them with their obligations, create moments with them ... these are the happiest moments of my day ".

In addition, Sophie said, "I like it when my son asks me to participate in his free time." I like to spend time and listen to how his day went."

\section{Theme 3: care and support}

The third main form respondents $(n=95)$ experienced positive support was by sharing care and support. This theme was mostly reported by Portuguese participants $\left(n_{\text {Port }}=39 ; n_{\text {Eng }}=38, n_{\text {Ger }}=18\right)$.

Lisa indicated that: "It is important to me, to have company, security, and especially ... love!" As Lisa revealed, relations with grandchildren were identified as positive due to the supportive nature of their ties: "I am divorced from my ex-husband but we feel loved the same way. There is a true effort to express care for us"

Supporting older adults or adult children is not felt to be an easy role. Both must be patient, listen to their stories and their experiences and support them in all their decisions. "My mother gave me a lot of affection when I was younger, she helped me make the most important decisions of my life and I'm very grateful for that. Now it's my turn to give all the love I've received to my children.", said Ellen excitedly.

Moreover, Lynn expressed she enjoyed receiving support in her daily activities. "Older adults are sometimes more vulnerable, however we have more experience. I miss the time when my daughter offered to take care of the garden for me and gave me her opinions about cooking and cleaning. We were best friends" added Nuria.

In a different perspective, Isabella verbalized: "I know my son does not want to be helped, because in a certain way he feels weak and useless for not being able to do what he used to do without difficulties, but he has to understand that I am there to help him even though he may not want my help."

\section{Conceptualizing conflict}

Older participants characterized intergenerational relationships with at least one of their adult children as being strained, tense or conflictual. English participants indicated the highest frequency of conflictual relationships (41.8\%), followed by German (40.0\%) and Portuguese (18.2\%) participants. Older adults conceptualized conflict in three themes: definition of limits, distance and alienation, and communication difficulties.

\section{Theme 1: definition of limits}

The majority of respondents $(n=226)$ described conflict in their relationships by defining the limits with their adult children. This theme was mostly reported by English participants $\left(n_{E n g}=111 ; n_{\text {Port }}=\right.$ $59, n_{\text {Germ }}=56$ ).

Participants shared different views on limits imposed by their adult children and about their own. In relation to this, Vasco reported: "I do not need my son to tell me what I cannot do. I'm old enough to know my limits." Additionally, aging may itself become a relevant contributor for definition of limits.

Sarah explained that: "I see that I have some problems in performing certain activities, such as cooking, doing sports, calculations. I need help from my children for those activities, but sometimes I insist on making my own things and I do recognize that I am not the same but I still would like to do everything as before." 
Participants also stressed that respecting decisions, confidentiality and privacy of their adult children was relevant for positive relationships with their children.

Anthony indicated that "I try not to impose my opinions on my children's lives. They are old enough to make decisions. Their privacy is more important to me than mine. Respecting limits of our children is necessary, so that they respect mine as well. We always got along well because of respect. We have very few conflicts". Anna added: "Everyone has different rules in life. Respecting them is essential for family relations. I always taught my children to be respectful and caring. Those can go together."

\section{Theme 2: distance and alienation}

Participants $(n=123)$ also experienced conflict in the relationship by feeling distant and alienated from family. This theme was mostly reported by German older participants $\left(n_{\text {Germ }}=76 ; n_{\text {Eng }}=43\right.$, $\left.n_{\text {Port }}=4\right)$.

Some participants verbalized their fear of not being relevant for family dynamics and their feeling of not belonging, “This is a moment of my life in which I think I am a burden in my daughter's life. I felt bad, so I started to distance myself to not create more problems" expressed George.

Some participants indicated geographic distance as the main contributor for feeling distant, isolated or alienated from relating to their children. This is especially notable for those whose children immigrated to a different country. Kimberly reported that: "I had to abdicate the company of my daughter when she accepted a new job in France. Our daily routines were replaced by long-distance phone calls and then an increasing distance and silence on the phone."

Family disputes and disagreements may also contribute to increased distance and alienation. Daniel verbalized that "Unfortunately I noticed that my son had a better relationship with his wife when I was away. I corrected his wife frequently and she questioned my opinions and decisions." Some participants indicated that children moved away from their older parents because of differences on raising their grandchildren. Mary indicated, "My daughter told me that I always insist on telling her how to raise [her] children, but she forgets that life has changed, so [she] will educate [her] children differently, in a more contemporary way."

Finally, non-normative events, such as widowhood were also associated with the isolation of older adults. In fact, the loss of a spouse may generate feelings of loneliness and abandonment. Bruno verbalized: "Since my wife died, I began to isolate myself and deprive myself of social activities.

\section{Theme 3: communication difficulties}

The third way respondents $(n=89)$ experienced conflict in the relationships with their children was by reporting communication difficulties. This theme was mostly reported by German participants $\left(n_{\text {Germ }}\right.$ $\left.=43 ; n_{\text {Eng }}=29, n_{\text {Port }}=17\right)$. A third of the participants $(27 \%)$ reported they did not feel their communication was being adequate or that they felt outdated in communicating.

Technology and social networks has been increasingly used by older adults to communicate with their children. Diana shared her difficulties in relation to new technologies: "It may be easy for you, click here and there, but for older adults it is very confusing. I feel I am outdated and that I cannot share more of my daughter's life because of this limitation."

Moreover, $17 \%$ of participants indicated that their difficulty in hearing and vision influenced communication with their children. "My vision is not the same and the way I express myself is not so clear as it used to be. Also, I often notice that I increase the volume of the TV and that it's too loud for my children." verbalized David. Additionally, Sandra noticed "that my children, often speak slower with me and that they try to use my vocabulary. And with my husband it's even worse." reported Fiona.

Participants indicated ambivalence by describing supportive and conflictual relationships simultaneously with their adult children. 


\section{Discussion}

Results show that participants used different dimensions of ambivalence to organize relationships, simultaneously, at the level of support and conflict.

Data analysis indicated six themes related, in a non-exclusive manner, to the perspectives of older adults (older adult-adult children interaction quality; family integration; care and support; definition of limits; distance and alienation; and communication difficulties). These perspectives correspond to two dimensions of ambivalence: the supportive and conflictual dimensions.

These results contribute to fill a gap in knowledge regarding the perspectives of older adults on intergenerational ambivalence, as well as to elaborate a comprehensive framework for each dimension.

The quality of the relations with their adult children was specially valued by the Portuguese and German participants. Participants described feelings of love and contentment, while at the same time feeling the will to share relevant moments of their lives with them. Considering there is a frequent decline in the quantity of social relations in old age, family relationships, especially between parents and children, are very significant for older adults (von Humboldt et al., 2013b).

Intergenerational relationships are long lasting, with a relevant impact on the health and well-being of older adults (Sharma et al., 2020; Cabras \& von Humboldt, 2021). Furthermore, the quality of the relations may be influenced by abusive treatment and tension from adult children (Albertini et al., 2007).

Some of these interviewees indicated that that their children give them consideration and opportunities to be integrated into the family. Portuguese participants showed the highest frequency of responses, including confidence and integration. Additionally, feeling integrated was often related to support to grandchildren.

Family integration is relevant for intergenerational relations (Agate et al., 2018; Rodrigues, 2013; von Humboldt et al., 2013c).

The existence of simultaneous conflictual and supportive experiences shows that there are ambivalent aspects when older adults begin to experience some contradictions arising from situations and expectations about feelings of their integration in the family (Costa \& von Humboldt, 2020; Torres et al., 2020).

Care and support was the least frequent theme concerning supportive relationships. Both Portuguese and English participants found it satisfying helping adult children with whom they have positive relationships or with their grandchildren. More than just responding to needs, solidarity theory indicates that support is higher in relationships with greater affection (von Humboldt et al., 2019). Family networks provide physical and emotional support to older adults, however, friends and neighbors are becoming an important part of social support networks (Rodrigues, 2013). Additionally, care and support is positively linked to good health and well-being in old age (Saraiva et al., 2015).

Establishing boundaries and defining limits with adult children was a pointed reason reason for family conflict. This theme was mainly reported by English participants. Healthy family relationships imply respect for older adults' decisions, as well as recognition of boundaries. In addition, $53.3 \%$ of the participants reported that it was necessary to impose limits to their adult children, in particular when in relation to providing support to grandchildren.

Relationships between older adults and their children can be perceived as of mutual support, a monetary co-dependence, since children often count on their support as parents and an affective codependency, where the children provide care to their older parents (Tarallo, 2015). Being present in the lives of children must be negotiated, as older adults are expected to maintain their independence (Breheny et al., 2013). Definition of limits and independence shows that parents can help children without being an obligation for them (Breheny et al., 2013).

These authors highlighted the need to focus on negotiating contexts that involve ambivalence and on developing strategies for discussing contradictions, rather than considering family relationships in terms of levels of solidarity (Connidis \& McMullin, 2002). 
German and English participants showed the highest number of replies concerning distance and alienation. While support was often demanded by adult children, older adults' sense of agency and participation in family decisions were not often considered, hence these participants felt neglected and alienated from their families.

Distance and alienation may imply dissatisfaction with family relationships (von Humboldt et al., 2013a). When distance and alienation is felt by older adults, mutual feelings of blame and guilt may manifest (Marques \& Sousa, 2012). Moreover, alienation may often occur after the rupture of a bond (e.g., divorce, death) (Santos et al., 2020).

The direct confrontation of adult children with some of the older parent behaviors may generate conflicts in the relationship, and avoidance and distance from the relationship is associated with a decline in stress and fewer depressive symptoms (Heid et al., 2017). Additionally, Gilligan et al. (2015) indicated that social norms may have played a more prominent role in distancing adult children and their fathers than their mothers.

Particularly German and English participants showed difficulties in communicating with adult children. These participants pointed out that communicating their feelings and daily needs was frequently difficult and tiring. They also indicated that communication rules were not always easy to understand and therefore felt misunderstood and that they did not understand their grandchildren's needs.

The quality of communication often depends on the interaction and support to older adults, that is, difficulties in communication are related to low levels of support and high level of conflict between older adults and their children (Birditt et al., 2012; Carneiro et al., 2019; Babnik et al. 2021). Additionally, when older adults are under conflict stress, they seem to have greater difficulty putting across concurrently positive and negative positions (Monteiro et al., 2018).

Although support was indicated by integration, care and quality of the relationship, older adultadult children ties were also typified as conflictual via distance, alienation, limits definition and communication difficulties. Findings reveal that the Portuguese participants showed the highest frequencies in the support dimension, while the German and the English participants indicated the highest frequencies in the conflict dimension.

Interpretation of the results of the present study is limited by several factors. By using a purposeful sample, the study may have involved knowledgeable participants. The authors propose that in the future, data should be analyzed in the long term, incorporating age-specific differences and phases of family life. Although currently studies that include measures of ambivalence are rare in gerontological studies, longitudinal studies may be useful in determining the direction of ambivalence. It may be possible to combine different national datasets using similar instruments, making it easier to do comparisons with international data.

In addition, these participants had a high average schooling, which could have led to more comprehensive aging prospects. Although we are sure achieved saturation in our subjects and that our results are reliable, our data analysis was based on older adults who volunteered, consequently, the results and conclusions below represent the sample from which they emerged and generalizations to other older populations should be done with caution. In addition, the total European cultural variety is not represented, since the participants show only three distinct nationalities.

This study did not include gender effects on intergenerational ambivalence. There is a need in future studies to consider gender effects upon family dynamics of separation between parents and children. Future studies about generation ambivalence should also focus on other dimensions present in intergenerational relations, including the combination of several quantitative and qualitative data (Gilligan et al., 2015).

This study included mostly female participants, resulting in gender-biased results. Future studies should also consider the degree of closeness between family members for more deeply understand intergenerational ambivalence.

Despite these limitations, this paper emphasizes that policy interventions can provide a comprehensive recognition of ways of experiencing the intergenerational ambivalence of older 
adults, considering an approach that distinguishes the various facets of ambivalence simultaneously. This article emphasizes the contradictory expectations of older adults with adult children regarding intergenerational relations. A qualitative method has shown that, in the past, different dimensions of ambivalence received little or no attention in this population. A key strength of this study is the fact that the participants, namely older English, German and Portuguese adults, have different cultures, thus contributing to knowledge in different cultures. Although this work does not give surety of clearcut indicators of intergenerational ambivalence among older adults, it offers a valuable attempt to elucidate how older adults experience intergenerational ambivalence in different cultures. Referring to the items of ambivalence experienced by older adults cross-nationally may help clarify the conceptual differences concerning this construct in future studies.

An important implication of this study is the need for improving education and exchanges between health care providers and older adults, so that intergenerational ambivalence is addressed, which can improve health care outcomes (Torres \& Cao, 2019; von Humboldt et al., 2018; von Humboldt, Ribeiro-Gonçalves et al., 2020; von Humboldt, Ribeiro-Gonçalves, Leal et al., 2020). Family crises, role conflict, intergenerational ambivalence, physical and mental health difficulties, and preexisting family conflicts can result in older adults needing professional support and training (Hayslip \& Fruhauf, 2019). Educational gerontologists may help older adults to foster personal growth and reconciliation of past difficulties, and to create new ways of interacting with their adult children (Hayslip \& Fruhauf, 2019; von Humboldt, 2016; von Humboldt et al., 2020). For example, intervention programs designed to teach specific skills to older adults to counteract psychosocial and contextual stressors are most needed (McLaughlin et al., 2017). These interventions may be combined with psychoeducational elements or supportive interventions, such as support groups (Hayslip \& Fruhauf, 2019).

This area of research contributes to understand and develop quality relationships within families with older adults. Valuable relationships are relevant for the well-being and health of older adults, and require continuous attention as they grow gradually more varied in different cross-cultural settings, with the ever-changing conventions, driving forces, prospects, and socio-demographic sceneries in old age.

\section{Disclosure statement}

The authors report no conflicts of interest. The authors alone are responsible for the content and writing of the paper.

\section{ORCID}

Sofia von Humboldt (iD) http://orcid.org/0000-0001-9664-6735

Isabel Leal (iD) http://orcid.org/0000-0002-1672-7912

\section{Sponsor's role}

The fund approved the design and aims of the study but did not play any role in the collecting of data, interpretation of results, or preparation of this article.

\section{References}

Agate, J. R., Agate, S. T., Liechty, T., \& Cochran, L. J. (2018). “Roots and wings”: Na exploration of intergenerational play. Journal of Intergenerational Relationships, 16(4), 395-421. https://doi.org/10.1080/15350770.2018.1489331

Albertini, M., Kohli, M., \& Vogel, C. (2007). Intergenerational transfers of time and money in European families: Common patterns-different regimes? Journal of European Social Policy, 17(4), 319-334. https://doi.org/10.1177/ 0958928707081068 
Babnik, K., Benko, E. \& von Humboldt, S. (2021). Ryff's psychological well-being scale. In D. Gu \& M. E. Dupre (Eds.), Encyclopedia of gerontology and population aging.(pp. 1-6). New York, NY: Springer, Cham [E-pub ahead of print]. http://dx.doi.org/10.1007/978-3-319-69892-2_89-1

Bengtson, V. L., \& Roberts, R. E. L. (1991). Intergenerational solidarity in aging families: An example of formal theory construction. Journal of Marriage and the Family, 53(4), 856-870. https://doi.org/10.2307/352993

Birditt, K. S., Tighe, L. A., Fingerman, K. L., \& Zarit, S. H. (2012). Intergenerational relationship quality across three generations. The Journals of Gerontology. Series B, Psychological Sciences and Social Sciences, 67(5), 627-638. https:// doi.org/10.1093/geronb/gbs050

Breheny, M., Stephens, C., \& Spilsbury, L. (2013). Involvement without interference: How grandparents negotiate intergenerational expectations in relationships with grandchildren. Journal of Family Studies, 19(2), 174-184. https:// doi.org/10.5172/jfs.2013.19.2.174

Brito, D. O., \& Faleiros, V. P. (2009). Representações da violência intrafamiliar por idosas e idosos [Representations of family violence by older women and men]. In V. P. Faleiros, A. M. L. Loureiro, \& M. A. Penso (Eds.), O conluio do silêncio: A violência intrafamiliar contra a pessoa idosa (pp. 1-20). Roca.

Cabras, E. \& von Humboldt, S. (2021). Motivation: theory/human model. In D. Gu \& M. E. Dupre (Eds.), Encyclopedia of gerontology and population aging (pp. 1-3). New York, NY: Springer, Cham [E-pub ahead of print]. https://doi.org/ 10.1007/978-3-319-69892-2_77-2

Cardoso, A. R. (2011). Avós no século XXI: Mutações e rearranjos na família contemporânea [Grandparents in the 21st century: Mutations and rearrangements in the contemporary family]. Juruá.

Carneiro, F., von Humboldt, S., \& Leal, I. (2014). Bem-estar subjetivo em idosas com e sem cancro da mama em remissão [Subjective well-being in older women with breast cancer in remission]. Psicologia, Saúde e Doenças, 15, $192-201$. http://dx.doi.org/10.15309/14psd150116

Carneiro, F. A., Costa, P. A., \& Leal, I. (2019). Psychometric analysis of the Portuguese version of the family sense of coherence. Psicologia, Saúde \& Doenças, 20(3), 838-858. http://dx.doi.org/10.15309/19psd200322

Cerveny, C. M. O., Macedo, R. M. S., \& Schalch, M. L. S. (2012). Família e longevidade [Family and longevity]. In C. M. O. Cerveny (Ed.), Família e ... : Intergeracionalidade, equilíbrio econômico, longevidade, repercussões, intervenções psicossociais, o tempo, filhos cangurus, luto, cultura, terapia familiar, desenvolvimento humano e social, afetividade, negociação (pp. 65-82). Casa do Psicologo.

Clarke, E. J., Preston, M., Raskin, J., \& Bengtson, V. L. (1999). Types of conflicts and tensions between older parents and adult children. The Gerontologist, 39(3), 261-270. https://doi.org/10.1093/geront/39.3.261

Costa, A., \& von Humboldt, S. (2020). A espiritualidade e as doenças crónicas nos idosos - Estudo exploratório em idosos [Spirituality and chronic diseases among older adults - Exploratory study with older adults]. Psicologia, Saúde e Doenças, 21(1), 69-74. http://dx.doi.org/10.15309/20psd210111

Dias, C. M. S. (2008). "Pais são para criar e avós para estragar": Será? ["Parents are to raise and grandparents to spoil”: Is it?]. In I. C. Gomes, E. F. M. Silvares, F. B. Assumpção Junnior, \& L. Preiszkulnik (Eds.), Família: Diagnóstico e abordagens terapêuticas (pp. 67-72). Guanabara Koogan.

Drew, L. M., \& Silverstein, M. (2007). Grandparents' psychological well-being after loss of contact with their grandchildren. Journal of Family Psychology, 21(3), 372-379. https://doi.org/10.1037/0893-3200.21.3.372

Gilligan, M., Suitor, J. J., \& Pillemer, K. (2015). Estrangement between mothers and adult children: The role of norms and values. Journal of Marriage and Family, 77(4), 908-920. http://dx.doi.org/10.1111/jomf.12207

Government Office for Science. (2015). Future of ageing: Relationships between the generations.

Hayslip, B., Jr, \& Fruhauf, C. A. (2019). Grandparenting: Influences on the dynamics of family relationships. Springer Publishing Company.

Heid, A. R., Zarit, S. H., \& Fingerman, K. L. (2017). Adult children's responses to parente "stubbornness". The Gerontologist, 53(3), 429-440. https://doi.org/10.1093/geront/gnv691

Kaufman, G., \& Elder, G. H., Jr. (2003). Grandparenting and age identity. Journal of Aging Studies, 17(3), $269-282$. https://doi.org/10.1016/s0890-4065(03)00030-6

Ka-Wing, L. O. (2017). Intergenerational ambivalence and family exchanges:Exploring grandparent childcare in Hong Kong and east Asia https://figshare.com/articles/Intergenerational_Ambivalence_and_Family_Exchanges_ Exploring_Grandparent_Childcare_in_Hong_Kong_and_East_Asia/5449936

Kunemund, H., Motel-Klingebiel, A., \& Kohli, M. (2005). Do intergenerational transfers from elderly parents increase social inequality among their middle-aged children? Evidence from the German aging survey. Journal of Gerontology: Social Sciences, 60(60b), 30-36. https://doi.org/10.1093/geronb/60.1.s30

Lendon, J. (2017). Trajectories of intergenerational ambivalence experienced by two cohorts of older parents and adult children. Journal of Family Issues, 38(3), 336-357. https://doi.org/10.1177/0192513X16634763

Lendon, J. P., Silverstein, M., \& Giarrusso, R. (2014). Ambivalence in older parent-adult child relationships: Mixed feelings, mixed measures. Journal of Marriage and Family, 76(2), 272-284. http://dx.doi.org/10.1111/jomf.12101

Lowenstein, A. (2007). Solidarity-Conflict and ambivalence: Testing two conceptual frameworks and their impact on quality of life for older family members. Journal of Gerontology: Social Sciences, 62B(2), 100-107. https://doi.org/10. $1093 /$ geronb/62.2.s100 
Lowenstein, A., Katz, R., \& Biggs, S. (2011). Rethinking theoretical and methodological issues in intergenerational family relations research. Ageing and Society, 31(7), 1077-1083. http://dx.doi.org/10.1017/S0144686X10000991

Luscher, K. (2000). Ambivalence. In S. Trnka (Ed.), Family issues between gender and generations (pp. 11-25). European Observatory on Family Matters at the Austrian Institute for Family Studies, European Commission, DirectorateGeneral for Employment and Social Affairs Unit E/1.

Luscher, K. (2004). Conceptualizing and uncovering intergenerational ambivalence. In K. Pilemer \& K. Luscher (Eds.), Intergenerational ambivalences (pp. 23-62). Elsevier.

Luscher, K., \& Lettke, F. (2004). Intergenerational ambivalence. In K. Pillemer \& K. Luscher (Eds.), Intergenerational ambivalences (pp. 153-179). Elsevier. https://doi.org/10.1111/j.1741-3737.2002.00585.x

Luscher, K. (2005). Looking at ambivalence. In R. Levy, P. Ghisletta, J.-M. Le Goff, D. Spini, \& E. Widmer (Eds.), Towards an interdisciplinary perspective on the life course (pp. 93-128). Elsevier.

Luscher, K., \& Pillemer, K. A. (1998). Intergenerational ambivalence: A new approach to the study of parent-child relations in later life. Journal of Marriage and Family, 60(2), 413-425. https://doi.org/10.2307/353858

McLaughlin, B., Ryder, D., \& Taylor, M. F. (2017). Effectiveness of interventions for grandparent caregivers: A systematic review. Marriage \& Family Review, 53(6), 509-531. https://doi.org/10.1080/01494929.2016.1177631

Mendoza-Ruvalcaba, N., von Humboldt, S., Arias-Merino, E. D., \& Leal, I. (2017). Cross-cultural differences in adjustment to aging: A comparison between Mexico and Portugal. Psychology, Community and Health, 6(1), 117127. http://doi.org/10.5964/pch.v6i1.179

Monteiro, A., von Humboldt, S., \& Leal, I. (2018). Crenças e atitudes dos cuidadores formais quanto à sexualidade dos idosos [Beliefs and attitudes of formal caregivers as to the sexuality of older adults]. Psicologia, Saúde \& Doenças, 19, 101-109. http://doi.org/10.15309/18psd190115

Park, S. M. (2014). Theory of intergenerational ambivalence: Is it the perfect new lens for studying intergenerational relationships? Journal of Population Ageing, 7(4), 323-334. https://doi.org/10.1007/s12062-014-9106-7

Pimentel, L. (2005). O lugar do Idoso na Família: Contextos e trajectórias. [The place of older adults in the family: Contexts and trajectories] ( $2^{\mathrm{a}}$ ed.). Quarteto.

Prinzen, K. (2014). Intergenerational ambivalence: New perspectives on intergenerational relationships in the German welfare state. Ageing and Society, 34(3), 428-451. https://doi.org/10.1017/s0144686x12001080

Rabelo, D. F., \& Neri, A. L. (2014). A complexidade emocional dos relacionamentos intergeracionais e a saúde mental dos idosos. [The emotional complexity of intergenerational relationships and older adults mental health]. Pensando Famílias, 18(1), 138-153. http://pepsic.bvsalud.org/pdf/penf/v18n1/v18n1a12.pdf

Rodrigues, S. S. (2013). A relação entre avós e netos após a separação conjugal dos pais. [The relationship between grandparents and grandchildren after the seperation of the parents]. Universidade de Lisboa.

Santos, I., von Humboldt, S., \& Leal, I. (2020). O efeito da imagem corporal e da satisfação conjugal no ajustamento ao envelhecimento dos idosos [The effect of physical image and marital satisfaction in the adjustment to aging of older adults]. Psicologia, Saúde e Doenças, 21(1), 111-116. http://dx.doi.org/10.15309/20psd210117

Saraiva, A. M., De Macêdo, W. M., Silva, J. B., Silva, P. M. C., Dias, M. D., \& Filha, M. O. F. (2015). Cares stories of institutionalized elderlies: Integrative practices as therapeutic possibilities. Revista De Enfermagem Da UFSM, 5(1), 131-140. https://doi.org/10.5902/2179769214211

Sechrist, J., Suitor, J. J., Pillemer, K., Gilligam, M., Howard, A. R., \& Keeton, S. A. (2012). Aging parents and adult children: Determinants of relationship quality. In R. Blieszner \& V. H. Bedford (Eds.), Handbook of families and aging (pp. 153-181). Praeger.

Sharma, S., Ferreira-Valente, A., de C. Williams, A. C., Abbott, J. H., Pais-Ribeiro, J., \& Jensen, M. P. (2020). Group differences between countries and between languages in pain-related beliefs, coping, and catastrophizing in chronic pain: A systematic review. Pain Medicine, 21(9), 1847-1862. https://doi.org/10.1093/pm/pnz373

Silverstein, M. (2006). Intergenerational family transfers in social context. In R. H. Binstock \& L. George (Eds.), Handbook of aging and the social sciences (pp. 165-180). Academic Press.

Silverstein, M., Conroy, S., Wang, H., Giarrusso, R., \& Bengtson, V. (2002). Reciprocity in parent - Child relations over the adult life course. Journal of Gerontology: Social Sciences, 57B(1), S3-S13. https://doi.org/10.1093/geronb/57.1.s3

Smith, P. K., \& Drew, L. M. (2004). Grandparenting and extended support networks. In M. Hoghughi \& \& N. Long (Eds.), Handbook of parenting: Theory and research for practice (pp. 146-159). Sage. https://doi.org/10.4135/ 9781848608160.n10

Steinbach, A. (2012). Intergenerational relations across the life course. Advances in Life Course Research, 17(3), 93-99. https://doi.org/10.1016/j.alcr.2012.06.002

Suitor, J., Sechrist, J., \& Pillemer, K. (2007). Withinfamily differences in mothers' support to adult children in Black andWhite families. Research on Aging, 29(5), 410-435. https://doi.org/10.1177/0164027507303636

Torres, M., von Humboldt, S., \& Leal, I. (2020). Estudo misto da influência das mudanças sexuais na satisfação sexual dos idosos [Mixed study about the influence of sexual changes in older adults' sexual satisfaction]. Psicologia, Saúde \& Doenças, 21(1), 90-96. http://dx.doi.org/10.15309/20psd210114

Torres, S., \& Cao, X. (2019). Improving care for elders who prefer informal spaces to age-separated institutions and health care settings. Innovation in Aging, 3(3), igz019. https://doi.org/10.1093/geroni/igz019 
von Humboldt, S., Carneiro, F., \& Leal, I., (2019). A structural model for adjustment to aging among older women in breast cancer remission. Applied Research in Quality of Life, 1-19. https://doi.org/10.1007/s11482-018-9622-3

von Humboldt, S., Carneiro, F., \& Leal, I. (2020). Older lesbian, gay, and bisexual adults: What predicts adjustment to aging? Sexuality Research and Social Policy, 1-7 [E-Pub Ahead of print]. https://doi.org/10.1007/s13178-020-00507-0 von Humboldt, S., \& Leal, I. (2014). Adjustment to aging in old adulthood: A systematic review. International Journal of Gerontology, 8(5), 108-113. http://dx.doi.org/10.1016/j.ijge.2014.03.003

von Humboldt, S., \& Leal, I. (2015a). The old and the oldest old: Do they have different perspectives on adjustment to aging? International Journal of Gerontology, 9(3), 156-160. http://dx.doi.org/10.1016/j.ijge.2015.04.002

von Humboldt, S., \& Leal, I. (2015b). The orientation to life questionnaire: Validation of a measure to assess older adults' sense of coherence. Educational Gerontology, 41(6), 451-465. http://dx.doi.org/10.1080/03601277.2014

von Humboldt, S., Leal, I., Laneiro, T., \& Tavares, P. (2013a). Examining occupational stress, sources of stress and stress management strategies through the eyes of Consultants: A multiple correspondence analysis for latent constructs. Stress \& Health, 29, 410-420. http://dx.doi.org/10.1002/smi.2487

von Humboldt, S., Leal, I., \& Pimenta, F. (2013b). Staying well in old age: Predicting older adults' wellness. Health SA Gesondheid, 18(1), 717-726. http://dx.doi.org/10.4102/hsag.v18i1.717

von Humboldt, S., Leal, I., \& Pimenta, F. (2014). Does spirituality really matter? - A study on the potential of spirituality to older adult's adjustment to aging. Japanese Psychological Research, 56, 114-125. http://dx.doi.org/10.1111/jpr

von Humboldt, S., Leal, I., \& Pimenta, F. (2015). Sense of coherence, sociodemographic, lifestyle, and health-related factors in older adults subjective well-being. International Journal of Gerontology, 9(1), 15-19. http://dx.doi.org/10. 1016/j.ijge.2014.01

von Humboldt, S., Leal, I., Pimenta, F., \& Niculescu, G. (2013c). In the eyes of older adults: Self-reported age and adjustment in African and European older adults. Health SA Gesondheid, 18(1), 712-722. http://dx.doi.org/10.4102/ hsag.v18i1.712

von Humboldt, S. (2016). Meaning and measurement of adjustment to aging in old age. In J. L. Powell \& S. Chen (Eds.), Conceptual and methodological issues on the adjustment to aging: Perspectives on aging well (pp. 47-83). New York, NY: Springer. http://dx.doi.org/10.1007/978-94-017-7576-2_3

von Humboldt, S., Low, L., \& Leal, I. (2020). Are older adults satisfied with their sexuality? Outcomes from a cross-cultural study. Educational Gerontology, 46(5), 284-293. https://doi.org/10.1080/03601277.2020.1744805

von Humboldt, S., Mendoza-Ruvalcaba, N., Arias-Merino, E., Costa, A., Cabras, E., Low, G., \& Leal, I. (2020). Smart technology and the meaning in life of older adults during the Covid-19 public health emergency period: A cross-cultural qualitative study. International Review of Psychiatry, 32 (7-8), 713-722. [E-Pub ahead of print]. https://doi.org/10.1080/09540261.2020.1810643

von Humboldt, S., Monteiro, A., \& Leal, I. (2018). How do older adults experience intergenerational relationships? Different cultures, ambivalent feelings. Educational Gerontology, 44(8), 501-513. https://doi.org/10.1080/03601277. 2018.1520528

von Humboldt, S., Ribeiro-Gonçalves, J. A., Costa, A., Low, G., \& Leal, I. (2020). Sexual expression in old age: How older adults from different cultures express sexually? Sexuality Research and Social Policy, 1-15. https://doi.org/10.1007/ s13178-020-00453-X

von Humboldt, S., Ribeiro-Gonçalves, J. A., \& Leal, I. (2020). Bullying in old age: A qualitative study on older adults'perceptions about being bullied. Journal of Interpersonal Violence, 1-24. https://doi.org/10.1177/ 0886260520943709

World Health Organization. (2018). Ageing and health. https://www.who.int/news-room/fact-sheets/detail/ageing-andhealth 